\title{
Produção de fitomassa, teor e produtividade do óleo essencial de Baccharis dracunculifolia DC. em função da adubação orgânica
}

\author{
SANTOS, R.F ${ }^{1 *}$; LIMA, L ${ }^{1}$; ALTIVO, F.S ${ }^{1}$; LALLA, J.G. ${ }^{1}$; MING, L.C. ${ }^{1}$ \\ ${ }^{1}$ UNESP - FCA - Campus Botucatu - Departamento de Produção Vegetal, Setor Horticultua. R. José Barbosa de \\ Barros, 1780, 18610-307, Botucatu-SP, *rosafs1208@yahoo.com.br
}

\begin{abstract}
RESUMO: Objetivou-se avaliar a produção de fitomassa, teor e produtividade do óleo essencial de Baccharis dracuculifolia DC., em função de doses de adubo orgânico, e foram utilizadas mudas produzidas por semente, e mantidas sob sombrite pelo período de 84 dias até serem transplantadas para o campo, no espaçamento de 1,0 x 1,0 m, com irrigação por gotejamento. $O$ delineamento estatístico utilizado foi em blocos ao acaso, com quatro repetições, e as doses de composto orgânico foram: 0, 10, 20, 30, 40 e 50 t ha- $^{-1}$. Foi realizada uma colheita, aos 150 dias após o transplante das mudas. O óleo essencial foi extraído por hidrodestilação e analisado em cromatógrafo a gás acoplado a espectrômetro de massas (Shimadzu, QP-5000). Todos os resultados foram submetidos à análise de variância pelo teste $\mathrm{F}$ seguido da análise de regressão e o teste Tukey para os dados: massa seca útil da parte aérea, teor e produtividade do óleo essencial. Para as variáveis massa seca total e massa seca útil da parte aérea, as dosagens estudadas influenciaram as plantas, que apresentaram os melhores resultados na dose $50 \mathrm{tha}$ 1. Para teor de óleo não houve influência significativa para as dosagens estudadas, porém a dose $30 \mathrm{t} \mathrm{ha}^{-1}$ apresentou o melhor resultado. Entretanto para a produtividade do óleo essencial, as dosagens estudadas influenciaram as plantas, que na dosagem 30 t ha $^{-1}$ obtiveram os melhores resultados.
\end{abstract}

Palavras-chave: Alecrim-do-campo, composto orgânico, plantas medicinais.

ABSTRACT: Phytomass production, content, and productivity of essential oil of Baccharis dracunculifolia DC. as affected by organic compound. The objective was to evaluate the characteristics of the Baccharis dracunculifolia DC., depending on levels of organic fertilizer, and seedlings were used $B$. dracunculifolia produced by seed, and kept under shade for a period of 84 days before being transplanted to the field, spaced $1.0 \times 1.0 \mathrm{~m}$, with drip irrigation. The experimental design was randomized blocks with four replications, and doses of organic compost, $0,10,20$, 30,40 and 50 t ha $^{-1}$. We performed a harvest, 150 days after transplanting. The essential oil was extracted by hydrodistillation and analyzed by gas chromatography coupled to mass spectrometer (Shimadzu, QP-5000). All results were submitted to analysis of variance F test followed by regression analysis and Tukey test for the data: useful dry mass of shoots, content of essential and productivity of essential oil. For the variables total dry mass and dry mass of shoots useful, the doses studied influenced the plants, which showed the best results at a dose $50 \mathrm{t}$ ha-1. For content of essential oil no significant influence was verified on the doses studied, but the dose 30 $\mathrm{t}$ ha ${ }^{-1}$ showed the best result. However the productivity of the essential oil, the doses studied influenced the plants, which in dose $30 \mathrm{t} \mathrm{ha}^{-1}$ obtained the best results.

Key words: Alecrim-do-campo, organic compound, medicinal plants.

\section{INTRODUÇÃO}

Plantas da Família Asteraceae têm sido amplamente estudadas quanto à sua composição química e atividade biológica, algumas têm proporcionado o desenvolvimento de novos fármacos e inseticidas, entre outros. Zomlefer (1994).

Alecrim-do-campo (Baccharis dracunculifolia

DC.), pertencente à essa família, é um arbusto lenhoso, nativo do Brasil, encontrado nas regiões Sul,

Recebido para publicação: agosto de 2011

Aceito para publicação: dezembro de 2011

Rev. Bras. PI. Med., Botucatu, v.13, especial, p.574-581, 2011. 
Sudeste se distribui até Argentina, Uruguai e Bolívia. Barroso (1976). Cresce principalmente campos abertos, pastagens abandonadas e áreas em processo de sucessão. Bastos (2001). A espécie é utilizada por suas propriedades analgésica, antiespasmódica, calmante, sedativa e citostática Lorenzi \& Matos (2002). Além disso, o alecrim-docampo (Baccharis dracunculifolia DC.), tem sido objeto de numerosos estudos entomológicos, pela sua riqueza de insetos herbívoros e galhadores destacando-se, principalmente, por sua relação peculiar com abelhas Apis mellifera. Bastos (2001). De acordo com Park et al. (2004), B. dracunculifolia é a principal fonte botânica da própolis "verde" produzida no sudeste brasileiro. Seus compostos, depois de processados pelas abelhas, têm a ação antibiótica e antiinflamatória.

O óleo essencial da $B$. dracunculifolia é considerado perfume exótico sendo exportado como matéria-prima para confecção de perfumes e tem como componentes majoritários os sesquiterpenos E-nerolidol e espatulenol. Queiroga (1989). Os óleos essenciais são obtidos por meio de destilação por arraste com vapor de água, de forma geral são misturas complexas de substâncias voláteis, lipofílicas, geralmente odoríferas, de aparência oleosa em temperatura ambiente, por isso a designação de óleo. O aroma agra-dável e intenso da maioria dos óleos voláteis é uma característica importante e, portanto, também cha-mados de essências. Huff (1999). Estudos sobre esse composto indicam seu efeito inibidor do crescimento do Plasmodium falciparum, o agente causador da malária Macedo et al. (2002) e de Leishmania amazonensis, causador da leishmaniose tegumentar americana. Arruda et al. (2005).

O aumento do uso de plantas na medicina torna mais evidente a necessidade destacada por Box (1973) de se produzir plantas medicinais, não somente considerando sua biomassa, mas principalmente os teores de princípios ativos contidos nela, atentando para o fato de que a síntese desses princípios ativos pode ser alterada conforme as técnicas de cultivo.

De acordo com Lorenzi e Matos (2002), quando plantas são cultivadas em solos de alta fertilidade, produzem folhas muito maiores que as observadas normalmente. Dentre os fatores que interferem na composição química de uma planta, a nutrição merece destaque, sendo que a deficiência ou excesso de nutrientes podem promover alterações na composição ou produção de fármacos na planta. É sabido que as adubações com nitrogênio mineral podem trazer problemas à produção de substâncias ativas, sendo recomendada sua aplicação via adubação orgânica. Pinto et al. (1999).

A adubação orgânica visa o aumento da produtividade no cultivo de plantas a partir do uso de resíduos de origem tanto animal, quanto vegetal. Ribeiro et al. (1999). Além de fornecer nutrientes, que são liberados pelo processo de mineralização, a adubação orgânica é fonte de energia para microorganismos úteis, melhorando a estrutura física do solo e aumentando a sua capacidade em reter umidade. Os adubos orgânicos possuem efeito regulador na temperatura do solo, retardam a fixação do fósforo e elevam a capacidade de troca catiônica do solo, reduzindo a lixiviação de nutrientes, como o potássio, o cálcio e o magnésio. Malavolta et al. (2002).

Plantas medicinais oriundas de cultivo orgânico são mais resistentes a pragas e doenças, reduzindo-se a necessidade de controle fitossanitário. Box (1973). Os adubos orgânicos e verdes, associados às práticas de agriculturas naturais, apresentam maior potencial de resposta econômica, devendo-se utilizar adubos minerais apenas quando a análise do solo demonstrar baixos teores de nutrientes. Corrêa Júnior et al. (1994).

Diante do exposto, os estudos das técnicas de cultivo na produção de fitomassa, no teor e produtividade do óleo essencial, contribuirão para o estabelecimento de parâmetros agronômicos no manejo desta espécie, tendo como objetivo no presente trabalho avaliar a produção de fitomassa, teor e produtividade do óleo essencial de Baccharis dracunculifolia DC. em função da adubação orgânica.

\section{MATERIAL E MÉTODO}

O experimento foi conduzido no pomar experimental do Departamento de Produção Vegetal - Setor Horticultura da Faculdade de Ciências Agronômicas-UNESP, Campus de Botucatu/SP, que apresenta as coordenadas geográficas: $22^{\circ} 5555$ $\mathrm{S}, 48^{\circ} 2622 \mathrm{O}$ e altitude $810 \mathrm{~m}$. O tipo climático predominante no local é o temperado quente (mesotérmico) com chuvas no verão e seca no inverno (Cwa - Koppen), tendo temperatura média anual de $20,5^{\circ} \mathrm{C}$ e precipitação pluviométrica média anual de $1533 \mathrm{~mm}$ (CUNHA et al., 1999). O solo da área foi classificado como Nitossolo Vermelho, segundo os critérios da Embrapa (2006). Conforme análise de solo realizada previamente, foi corrigida V\% para $70 \%$ por meio da aplicação de calcário Fuller PRNT 100\%, sendo utilizado $2 \mathrm{t} \mathrm{ha}^{-1}$ deste calcário. O solo foi arado e gradeado para o plantio. A análise química do solo foi realizada de acordo com a instrução normativa DAS 28 de 27/07//2007, Mapa (2007).

Foram utilizadas mudas de alecrim do campo produzidas por sementes, de uma população espontânea de Botucatu (São Paulo) (S 22ํ50' 54,0"; WO 48 26' 04,2"), coletadas em maio de 2009. As plantas foram identificadas e as exsicatas foram

Rev. Bras. PI. Med., Botucatu, v.13, especial, p.574-581, 2011. 
depositadas no Herbário do Instituto de Biociências da UNESP de Botucatu, sob o número BOTU 027340 para as plantas femininas e BOTU 027341 para as plantas masculinas. Após a coleta as inflorescências foram colocadas em bandejas plásticas e secas à sombra, em temperatura ambiente (média de $22^{\circ} \mathrm{C}$ ), e submetidas à debulha manual para a separação das sementes. As sementes foram colocadas para germinar em tubetes cilindro-cônicos de polietileno com volume de $50 \mathrm{~cm}^{3}$, preenchidos com substrato comercial Carolina Soil ${ }^{\circ}$, mantidas sob casa-devegetação com luminosidade de $50 \%$, sendo irrigadas diariamente por nebulização intermitente a cada quinze minutos até o transplantio das mudas para o campo.

O plantio definitivo foi realizado em covas, no espaçamento de 1,0 x 1,0 m, entre plantas e linhas, com irrigação por gotejamento, aos 84 dias após a semeadura das sementes (DAS). 0 delineamento experimental utilizado foi em blocos ao acaso, com seis tratamentos que foram diferentes doses de composto orgânico: 0, 10, 20, 30, 40 e 50 t ha ${ }^{1}$ com quatro repetições. Cada parcela foi constituída por 12 plantas, totalizando 288 plantas úteis. Foram plantadas mudas de alecrim do campo, também em volta de todo o experimento, ou seja, 239 plantas em toda a borda, num total de 527 plantas, com área total de $527 \mathrm{~m}^{-2}$.

As características químicas do solo foram: $\mathrm{pH}$ em $\mathrm{CaCl}_{2}=5,1$; matéria orgânica $\left(\mathrm{g} \mathrm{dm}^{-3}\right)=18 ; \mathrm{P}$ resina $\left(\mathrm{mg} \mathrm{dm}^{-3}\right)=13 ; \mathrm{H}+\mathrm{Al}, \mathrm{K}, \mathrm{Ca}$ e $\mathrm{Mg}$ (mmolc $\left.\mathrm{dm}^{3}\right)=38 ; 2 ; 27 ; 13$; capacidade de troca de cátions CTC 80; saturação em bases V $(\%)=53$; Boro, Cobre, Ferro, Manganês e Zinco $\left(\mathrm{mg} \mathrm{dm}^{-3}\right)=0,13 ; 0,74 ; 23$; $5 ; 2,9$.

A matéria prima, resíduos de origem vegetal e animal para o experimento de compostagem foi obtida junto à Centroflora Anidro do Brasil e ao confinamento dos novilhos precoces da UNESP de Botucatu, respectivamente. Os resíduos vegetais da produção de extratos botânicos disponíveis que foram fornecidos pela Centroflora - Anidro do Brasil são oriundos da mistura das seguintes espécies: 1 Pilocarpus microphyllus Stapf ex Wardleworth, 2 Aesculus hippocastanum L., 3 - Atropa belladona L., 4 - Trichilia emarginata (Turcz.) C. DC., 5 Passiflora alata Curtis, 6 - Paullinia cupana Kunth. Os resíduos foram secos até a eliminação do solvente e montados em pilhas com aproximadamente $5 \mathrm{~m}^{3}$. Esterco de curral foi adicionado a fim de balancear a relação $\mathrm{C} / \mathrm{N}$ para $35 / 1$, em função das análises químicas, objetivando-se finalizar o processo de compostagem com o máximo de $\mathrm{C} / \mathrm{N}$ de $18 / 1$. kiehl (2002). O manejo das pilhas foi conduzido conforme Kiehl (1985). Foram avaliadas, durante o processo de compostagem três amostras coletadas em cada pilha ao final de 90 dias, quando os compostos já estavam prontos para determinação dos minerais, nitrogênio total, carbono orgânico total e $\mathrm{pH}$, de acordo com Laboratório Nacional de Referência Vegetal (1988). Com base nestes resultados os fertilizantes obtidos foram caracterizados como fertilizante orgânico misto de acordo com o Art. $2^{\circ}$ classe "A" e enquadrado nos demais itens seguindo a Instrução normativa $\mathrm{N}^{\circ} 23$ de 31 de agosto de 2005 da Secretaria de defesa agropecuária do Ministério da Agricultura e Abastecimento em acordo com o Decreto no 5.351, de 21 de janeiro de 2005. A análise química do composto foi realizada de acordo com metodologia descrita por Raij (2001). O composto orgânico apresentou as seguintes características químicas: matéria orgânica $(\%)=38$; relação carbono nitrogênio $\mathrm{C} / \mathrm{N} \mathrm{10/1}$; $\mathrm{pH}$ em água $=7,4 ; \mathrm{N}, \mathrm{P}_{2} \mathrm{O}_{5}, \mathrm{~K}_{2} \mathrm{O}$, $\mathrm{Ca}, \mathrm{Mg}$, (\% na matéria seca $)=2,2 ; 0,54 ; 0,30 ; 1,9$; 0,2; Cobre, Zinco, Ferro e Manganês, $\left(\mathrm{mg} \cdot \mathrm{kg}^{-1} \mathrm{na}\right.$ matéria seca $)=26 ; 112 ; 7339 ; 279$.

A área de cultivo foi conduzida dentro dos critérios de boas práticas agrícolas sendo mantida limpa de invasoras por capina manual e com roçadeiras. Foi realizada uma colheita, aos 150 dias após o transplante das mudas (DAT). O corte foi realizado com tesouras de poda e podão, cortandose as plantas na altura de aproximadamente $30 \mathrm{~cm}$. Logo após a colheita, no laboratório do Departamento de Produção Vegetal - Setor Horticultura - FCA UNESP - Botucatu/SP, as plantas foram acondicionadas em sacos de papel, devidamente identificadas e colocadas para secagem em estufa de circulação forçada de ar, em temperatura controlada a $40^{\circ} \mathrm{C}$, até a obtenção de massa seca constante, determinando-se o peso da massa seca útil da parte aérea, que foi definida como caule de até 2 milímetros de diâmetro e 15 centímetros de comprimento aproximadamente, ainda verde e com folhas, por ser esta a parte da planta produtora de óleo essencial.

A extração do óleo essencial foi realizada no Laboratório de Produtos Naturais, do Centro de Pesquisa e Desenvolvimento de Recursos Genéticos Vegetais do Instituto Agronômico de Campinas, Campinas - SP, de setembro de 2010 a janeiro de 2011. O óleo essencial foi extraído por hidrodestilação, em aparelho tipo Clevenger. Craveiro et al. (1981), utilizando-se $50 \mathrm{~g}$ de massa seca útil da parte aérea em $2 \mathrm{~L}$ de água destilada por duas horas.

As variáveis analisadas foram massa seca total, massa seca útil da parte aérea em quilos por hectare, o teor do óleo essencial em percentual e a produtividade do óleo essencial em quilos por hectare.

Todos os resultados foram submetidos à análise de variância pelo teste $\mathrm{F}$ seguido da análise de regressão, e o teste Tukey para os dados: massa seca útil da parte aérea, teor e produtividade do óleo essencial (Banzatto \& Kronka, 1995). 


\section{RESULTADO E DISCUSSÃO}

Para a característica massa seca total verificou-se diferença estatística significativa entre as doses avaliadas $(P<0,05)$ e através da análise de regressão observou-se aumento linear na produção em torno de $2500 \mathrm{~kg} \mathrm{ha}^{-1}$ em função das diferentes doses de composto orgânico (Figura 1), que inclui caule, folha e inflorescência. A menor média estimada foi de $1432,28 \mathrm{~kg} \mathrm{ha}^{-1}$, sem o uso de composto orgânico e a maior média de $3.865,14 \mathrm{~kg} \mathrm{ha}^{-1}$, obtida na dose $50 \mathrm{t} \mathrm{ha}^{-1}$.

A massa seca útil da parte aérea, apresentou diferença estatística significativa entre as doses avaliadas $(P=0,0001)$ (Tabela 1) e através da análise de regressão observou-se aumento linear na produção em torno de $858,12 \mathrm{~kg} \mathrm{ha}^{-1}$ em função das diferentes doses de composto orgânico, não sendo possível determinar pelas dosagens estudadas se existe ou não ponto de máxima produção que a partir dela ocorra decréscimo na massa se útil da parte aérea. A menor média estimada foi de $508,56 \mathrm{~kg} \mathrm{ha}$ ${ }^{1}$, sem o uso de composto orgânico e a maior média de $1.366,68 \mathrm{~kg} \mathrm{ha}^{-1}$, obtida na dose $50 \mathrm{t} \mathrm{ha}^{-1}$ (Figura 2). O melhor resultado de massa seca útil da parte aérea pode ser explicado provavelmente, pela maior disponibilidade de nutrientes ocasionado pelas doses crescentes de composto orgânico. Benedetti et al. (2009) observaram que a utilização de adubos, tanto orgânico quanto mineral, associados à correção do solo demonstrou eficiência em estimular o desenvolvimento de espinheira-santa, para a massa seca da parte aérea e que na ausência da calagem a adubação orgânica mostrou-se mais favorável em estimular o desenvolvimento das plantas. Influência positiva das doses de adubação com esterco bovino e de galinha foi constatada por Costa (2008) sobre o acúmulo de biomassa seca, rendimento e composição química do óleo essencial de elixir paregórico (Ocimum sellol), sendo que os maiores valores foram obtidos com a utilização de esterco bovino nas doses entre 8 e $10 \mathrm{~kg} \mathrm{~m}^{-2}$ e esterco avícola nas doses entre 4 e $5 \mathrm{~kg} \mathrm{~m}^{-2}$. Observa-se também que conforme ocorreu aumento das doses de composto orgânico, maior foi a quantidade de nitrogênio disponível, o que corrobora com os resultados obtidos por Chaves (2002) no primeiro corte de Ocimum gratissimum, afirmando que as doses crescentes de adubação orgânica, favoreceram o incremento na produção de caules, folhas e inflorescências. O efeito das doses de matéria orgânica no aumento de produção de fitomassa já foi registrado para Hyptis suaveolens Maia (2006) atribuindo-se à crescente disponibilidade e à absorção de nutrientes. Entretanto, este comportamento não é constante, pois em Justicia pectoralis as doses de adubações orgânicas e minerais não influenciaram a produção de biomassa da planta. Bezerra et al. (2006).

Como as doses crescentes de composto orgânico podem ter disponibilizado maiores teores de nutrientes como: o $\mathrm{N}$ que é responsável pelo crescimento da parte aérea e junto com o Mg faz parte da molécula de clorofila, favorecendo maior atividade fotosintética; o $\mathrm{P}$ responsável pela síntese de carboidratos fornecendo energia para o crescimento das plantas; o K que aumenta a translocação de açúcares para as regiões de crescimento; o Ca favorecendo a absorção de íons, responsável pelo crescimento das raízes; e os

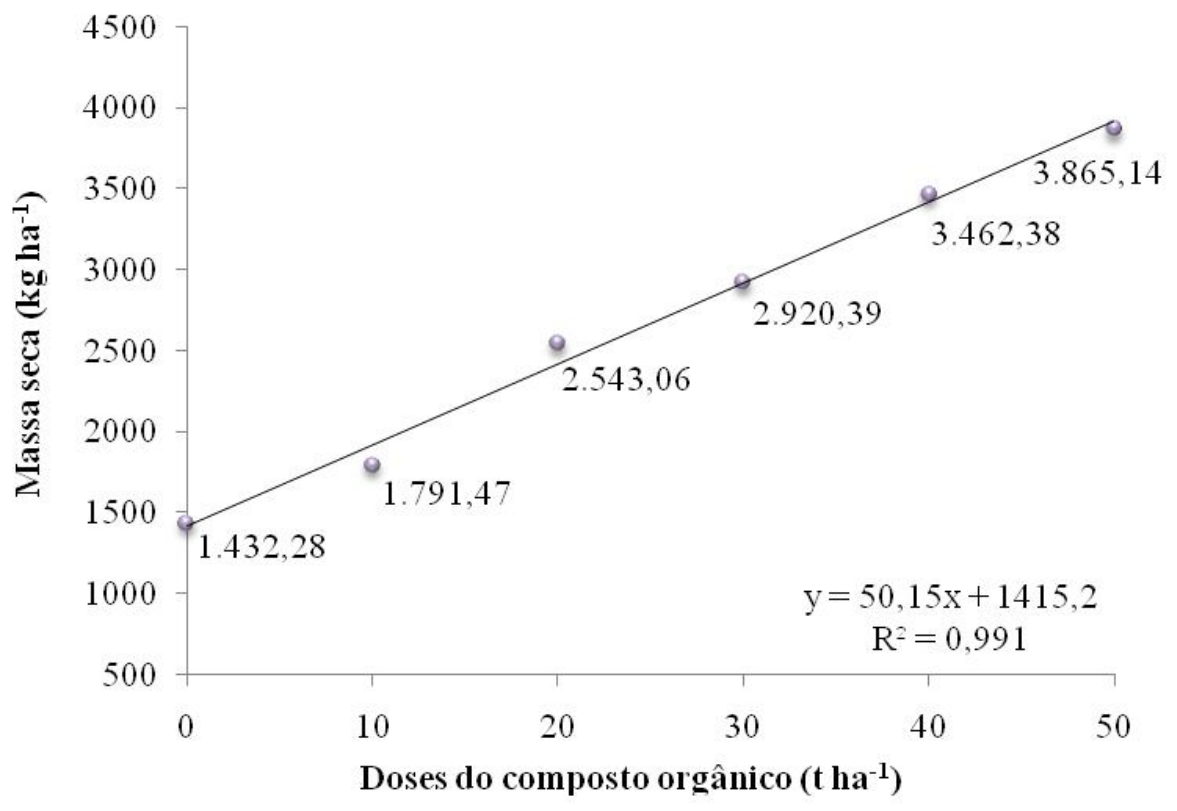

FIGURA 1. Produção de massa seca total em $\mathrm{kg}^{-1}$ de $B$. dracunculifolia, avaliadas em doses crescentes de composto orgânico: 0, 10, 20, 30, 40 e 50 t ha-1 $^{-1}$, aos 150 DAT (dias após o transplante), Botucatu, SP, 2010.

Rev. Bras. PI. Med., Botucatu, v.13, especial, p.574-581, 2011. 


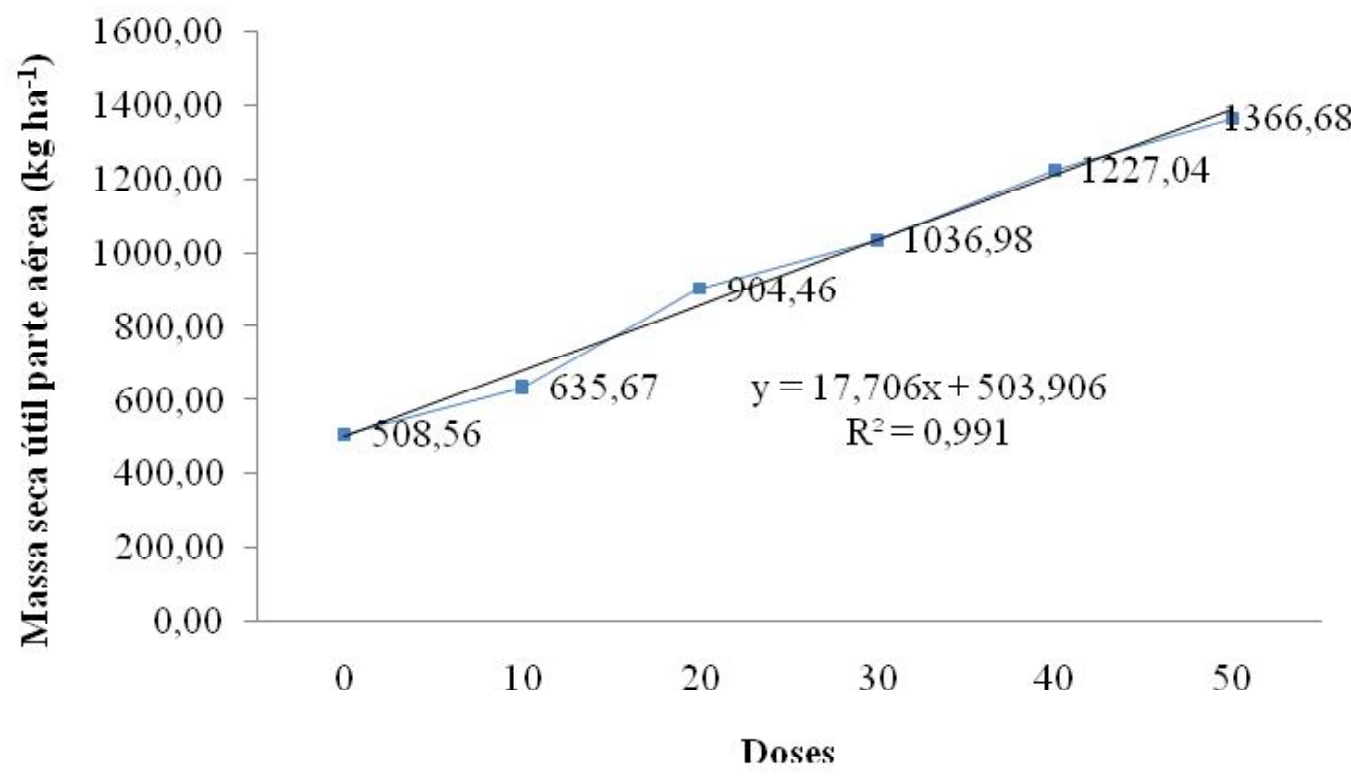

FIGURA 2. Produção de massa seca útil, da parte aérea, em $\mathrm{kg} \mathrm{ha}^{-1}$ de $B$. dracunculifolia, avaliadas em doses crescentes de composto orgânico: 0, 10, 20, 30, 40 e 50 t ha $^{-1}$, aos 150 DAT (dias após o transplante), Botucatu, SP, 2010.

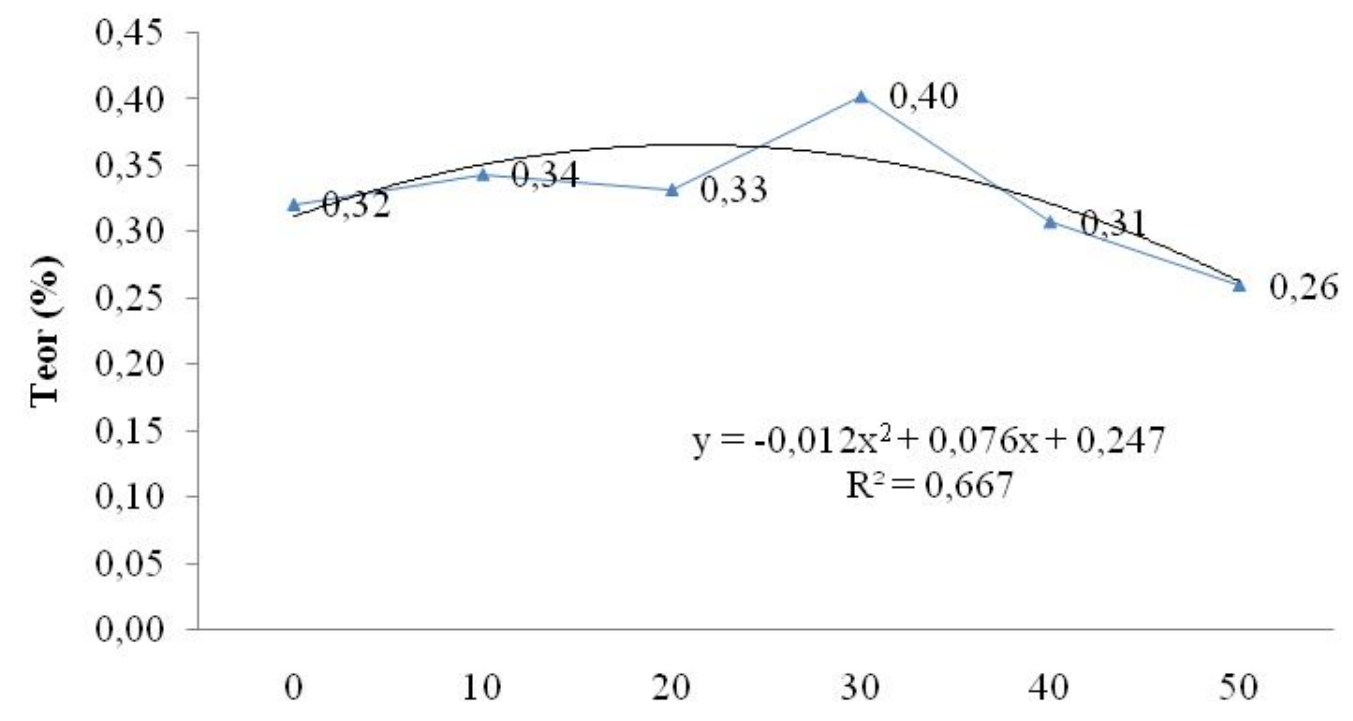

\section{Doses}

FIGURA 3. Teor de óleo essencial de folha de $B$. dracunculifolia, avaliadas em doses crescentes de composto orgânico: 0, 10, 20, 30, 40 e 50 t ha-1 aos 150 DAT (dias após o transplante), Botucatu, SP, 2010.

micronutrientes ferro, manganês e cobre ativando várias enzimas; e a presença de todos estes nutrientes no composto orgânico utilizado pode ter influenciado no aumento linear da produção, desta característica analisada, neste trabalho

Em relação ao teor de óleo essencial (\%) não houve diferença estatística significativa entre as doses testadas $(P>0,05)$ (Tabela 1$)$. A equação que mais se adequou aos dados foi a obtida pelo ajuste da regressão polinomial (Figura 3$)\left(R^{2}=0,667\right)$. Observou-se o aumento gradativo nesta característica com o acréscimo da dose de composto orgânico, sendo que a dose avaliada que proporcionou maior teor em porcentagem de óleo essencial foi a de $30 \mathrm{t}$ ha $^{-1}$ com $0,40 \%$ de óleo essencial (incremento de $14 \%$ em relação à testemunha) e que um aumento da adubação a partir desse ponto causou diminuição neste parâmetro. Esses resultados estão de acordo com o exposto em Ming (1994), que verificou aumento no rendimento de biomassa e decréscimo no teor de óleo essencial em Lippia alba à medida que se incorporava ao solo doses crescentes de esterco e 


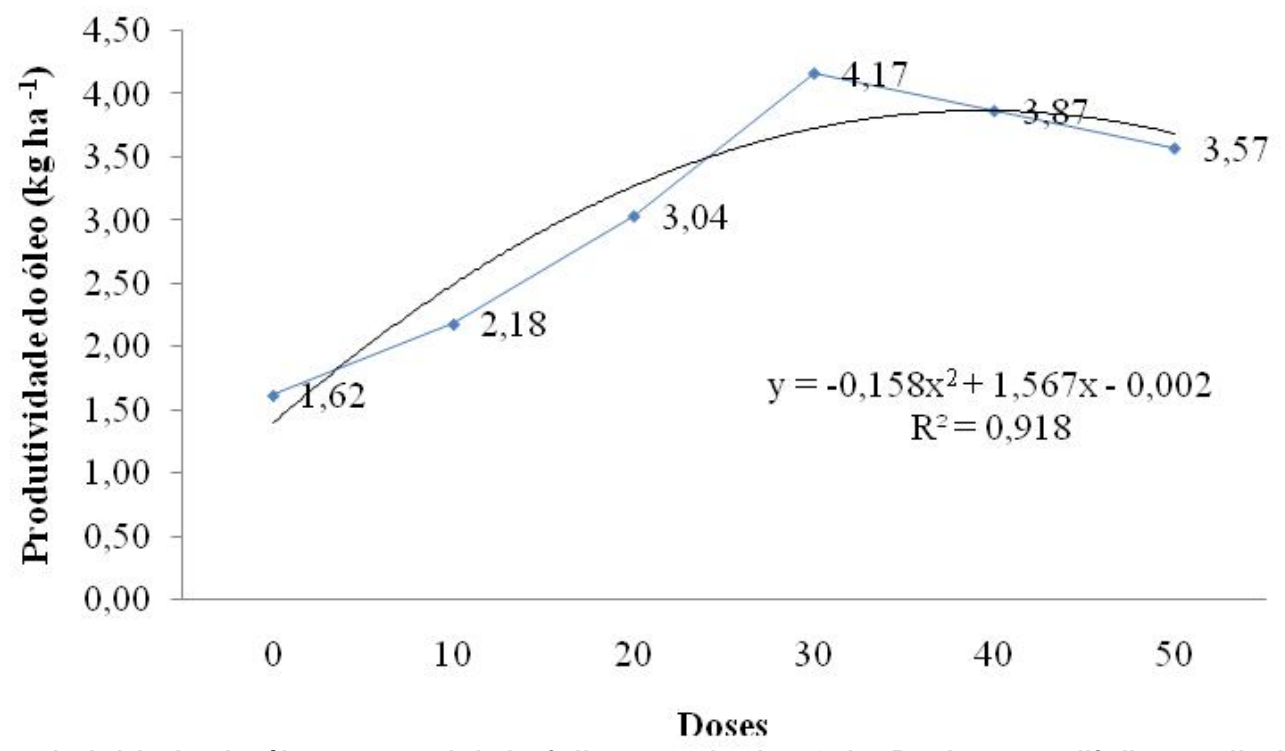

FIGURA 4. Produtividade de óleo essencial de folhas em $\mathrm{kg}^{-1}$ de $B$. dracunculifolia, avaliadas em doses crescentes de composto orgânico: 0, 10, 20, 30, 40 e 50 t ha-1 $^{-1}$, aos 150 DAT (dias após o transplante), Botucatu, SP, 2010.

TABELA 1. Médias (teste Tukey) massa seca útil da parte aérea, teor (\%) e produtividade em $\mathrm{kg} \mathrm{ha}^{-1}$ do óleo essencial de $B$. dracunculifolia avaliadas em doses crescentes de composto orgânico: 0, 10, 20, 30, 40 e 50 t ha', aos 150 DAT (dias após o transplante), cultivadas em Botucatu, SP.

\begin{tabular}{cccc}
\hline Doses & $\begin{array}{c}\text { Massa seca útil } \\
\text { Parte Aérea }\end{array}$ & $\begin{array}{c}\text { Teor } \\
(\%)\end{array}$ & $\begin{array}{c}\text { Produtividade do óleo } \\
\left(\mathbf{k g ~ h a}^{-\mathbf{1}}\right)\end{array}$ \\
\hline 0 & $508,56 \mathrm{~d}$ & $0,32 \mathrm{a}$ & $1,62 \mathrm{c}$ \\
10 & $635,67 \mathrm{~d}$ & $0,34 \mathrm{a}$ & $2,18 \mathrm{bc}$ \\
20 & $904,46 \mathrm{c}$ & $0,33 \mathrm{a}$ & $3,04 \mathrm{abc}$ \\
30 & $1036,98 \mathrm{bc}$ & $0,40 \mathrm{a}$ & $4,17 \mathrm{a}$ \\
40 & $1227,04 \mathrm{ab}$ & $0,31 \mathrm{a}$ & $3,87 \mathrm{ab}$ \\
50 & $1366,68 \mathrm{a}$ & $0,26 \mathrm{a}$ & $3,57 \mathrm{ab}$ \\
$\mathbf{P}$ & $\mathbf{0 , 0 0 0 1}$ & $\mathbf{0 , 1 3 5 1}$ & $\mathbf{0 , 0 0 2 6}$ \\
\hline $\mathbf{C V}(\%)$ & $\mathbf{1 1 , 6 9}$ & $\mathbf{1 9 , 8 4}$ & $\mathbf{2 6 , 0 3}$ \\
\hline
\end{tabular}

Médias seguidas de letras iguais na coluna não diferiram estatisticamente entre si pelo teste Tukey $(P>0,05)$.

com os resultados encontrados por Chaves et al. (1998) que também observaram aumento na produção de matéria seca da parte aérea em Mentha arvensis var. piperacens e M. villosa com o uso de $6 \mathrm{~kg} \mathrm{~m}^{-2}$ de esterco bovino, enquanto o teor de óleo essencial reduziu progressivamente com o aumento das doses do esterco. Silva et al. (2006) demonstraram que o teor de óleo essencial extraído da biomassa seca foliar aumentou com as doses de adubo, atingindo o valor máximo de $0,23 \mathrm{~g}$ planta-1 $^{-1} \mathrm{com} 8,1 \mathrm{~kg} \mathrm{~m}^{-2}$ de esterco bovino e $0,31 \mathrm{~g} \mathrm{planta}^{-1} \mathrm{com} 4,0 \mathrm{~kg} \mathrm{~m}^{-2}$ de esterco avícola. Resultado diferente foi observado por Nascimento e Fávero (2003), onde verificaram que o teor do óleo essencial da parte aérea (folhas e inflorescências) de Ocimum basilicum não foi influenciado pelas doses de matéria orgânica (húmus). Da mesma forma Santos; Innecco (2004) verificaram que a produção de óleo essencial em folhas Lippia alba também não foi influenciada pela adubação orgânica. Segundo Sangwan et al. (2001), a aplicação de fertilizantes minerais ou orgânicos em plantas medicinais normalmente afeta a produtividade de óleos essenciais devido ao maior acúmulo de biomassa, o que pode explicar o aumento na produção de biomassa e o decréscimo no teor do óleo essencial neste estudo. Estes dados demonstram que não há um padrão na resposta das plantas, de uso medicinal, cultivadas com diferentes níveis de adubos orgânicos, evidenciando a necessidade de mais pesquisas nesta área devido 
ao crescente interesse por informações sobre cultivo de plantas produtoras de metabólitos especializados.

Quanto à produtividade em $\mathrm{kg}$ de óleo essencial por hectare (Figura 4) foi observada a mesma tendência que a característica teor de óleo essencial (\%), porém apresentou diferença estatística significativa entre as doses avaliadas $(P=0,0026)$ (Tabela 1). Conforme o aumento das aplicações do composto orgânico houve incremento na produtividade de $2,55 \mathrm{~kg} \mathrm{ha}^{-1}$ a mais que a testemunha ( $\left.0 \mathrm{t} \mathrm{ha}^{-1}\right)$, atingindo $4,17 \mathrm{~kg}$ de óleo ha-1 quando utilizada $30 \mathrm{t}$ ha $^{-1}$ de composto orgânico. Quando aplicados $40 \mathrm{e}$ 50 t ha ${ }^{1}$ de composto orgânico as tendências das produtividades são decrescentes. O decréscimo na produtividade do óleo essencial pode ser atribuído como resposta ao estress nutricional ocasionado pelo excesso de nutrientes. Em estudos sobre a adubação orgânica em orégano, Corrêa et al. (2010) concluíram que a adubação orgânica com esterco bovino e cama de aves influenciaram significativamente a biomassa seca de plantas de orégano, o teor e a produtividade do óleo essencial. Os mesmos autores recomendam as doses de $12 \mathrm{~kg} \mathrm{~m}^{-2}$ de esterco bovino e $4,37 \mathrm{~kg}$ de esterco de aves para obtenção de maiores e rendimento de óleo essencial de orégano. Oliveira Júnior et al. (2005), estudando o efeito da adubação com e sem calagem interagida com adubação orgânica e química, mostraram que o teor de óleo essencial de arnica (Lychnophora pinaster) decresceu com a elevação da disponibilidade de nutrientes para as plantas. Além de estar relacionada ao genótipo a recomendação de adubos orgânicos visando teor e produtividade de óleo essencial depende da fonte e da dosagem.

Conclui-se que para o parâmetro massa seca total e massa seca útil da parte aérea, as dosagens estudadas influenciaram as plantas, que apresentaram os melhores resultados na dose $50 \mathrm{t}$ ha $^{-1}$. Para o teor de óleo essencial pôde-se observar que não houve diferença estatística significativa, porém a dose $30 \mathrm{t} \mathrm{ha}^{-1}$ apresentou o melhor resultado. Entretanto a variável produtividade do óleo essencial, as dosagens estudadas influenciaram as plantas, que na dosagem $30 \mathrm{t} \mathrm{ha}^{-1}$ obtiveram os melhores resultados.

\section{REFERÊNCIA}

ARRUDA,D.C.; D'ALEXANDRI,A.M.K.; ULIANA,S.R.B. Antileishmanial activity of the terpene nerolidol. Antimicrobial Agents and Chemotherapy, Bethesda, v. 49, n. 5, p. 1679-1687, 2005.

BARROSO,G. Compositae: subtribo Bacchariridinae Hoffman. Estudo das espécies ocorrentes no Brasil. Rodriguesia, Rio de Janeiro, v. 10, p. 7-273, 1976. BANZATTO, D. A.; KRONKA, S. N. Experimentação agrícola. 3. ed. Jaboticabal: Funep,1995, 247 p.
BASTOS, E.M.A.F. Origem botânica e indicadores de qualidade da "própolis verde" produzida no Estado de Minas Gerais, Brasil. 2001. 137 f. Tese (Doutorado em Entomologia)-Faculdade de Filosofia Ciências e Letras de Ribeirão Preto, Universidade de São Paulo, Ribeirão Preto, 2001.

BENEDETTI, E.L. Calagem e adubação no crescimento de Espinheira-santa [Maytenus ilicifolia (Schrad.) Planch.] em casa de vegetação. Revista Brasileira de Plantas Medicinais, Botucatu, v. 11, n. 3, 2009.

BEZERRA, A.M.E. et al. Rendimento de biomassa, óleo essencial, teores de fósforo e potássio de chambá em resposta à adubação orgânica e mineral. Revista Ciência Agronômica, Fortaleza, v. 37, n. 2, p. 124-129, 2006. BOX, M. Cultivo de plantas medicinais. Madri: Labor, 1973. 490 p.

CHAVES, F.C.M. Produção de biomassa, rendimento e composição de óleo essencial de alfavaca-cravo (Ocimum gratissimum L.) em função da adubação orgânica e épocas de corte. 2002. 153 f. Tese (Doutorado em Agronomia/ Produção Vegetal)-Faculdade de Ciências Agronômicas, Universidade Estadual Paulista, Botucatu, 2002.

CHAVES, F.C. M.; MATTOS, S.H.; INNECCO, R. Adubação orgânica em hortelã-rasteira (Mentha $\mathrm{x}$ villosa Huds). Horticultura Brasileira, Brasília, DF, v. 16, n. 1, 1998. CORRÊA JÚNIOR, C.; MING, C.L.; SCHEFFER, M.C. Cultivo de plantas medicinais, condimentares e aromáticas. 2 ed. Jaboticabal: FUNEP,1994, 126 p. CORRÊA, R.M. et al. Adubação orgânica na produção de biomassa de plantas, teor e qualidade de óleo essencial de orégano (Origanum vulgare L.) em cultivo protegido. Revista Brasileira de Plantas Medicinais, Botucatu, v. 12, n. 1, p. 80-89, 2010.

COSTA, L.C.B. Tipos e doses de adubação orgânica no crescimento, no rendimento e na composição química do óleo essencial de elixir paregórico. Ciência Rural, Santa Maria, v. 38, n. 8, p. 2173-2180, 2008.

CRAVEIRO, A.A. et al. Óleos essenciais de plantas do Nordeste. Fortaleza: UFC, 1981. 210 p.

CUNHA, A. R. et al. Classificação climática para o município de Botucatu, SP, segundo Köppen. In: SIMPÓSIO EM ENERGIA NA AGRICULTURA, 1., 1999, Botucatu. Anais... Botucatu: Faculdade de Ciências Agronômicas, 1999. p. 490-491.

EMBRAPA. Centro Nacional de Pesquisa de Solos. Sistema Brasileiro de Classificação de Solos. 2. ed. Rio de Janeiro: EMBRAPA SOLOS, 2006. 306 p.

HUFF, G.F. Farmacognosia: Da Planta ao Medicamento. 1. ed. Rio Grande do Sul: Ed. UFRGS, 1999. 821 p.

KIEHL, E.J. Manual de compostagem maturação e qualidade do composto. Piracicaba: Ed. do autor, 2002. $171 \mathrm{p}$.

KIEHL, E.J. Fertilizantes orgânicos. Piracicaba: Ceres, 1985. 492 p.

LABORATÓRIO NACIONAL DE REFERÊNCIA VEGETAL. Análise de corretivos, fertilizantes e inoculantes: métodos oficiais. Brasília, DF: Ministério de Agricultura, 1988. $104 \mathrm{p}$.

LORENZI, H; MATOS,F.J.A. Plantas medicinais no Brasil: nativas e exóticas. Nova Odessa: Instituto Plantarum, 2002. $511 \mathrm{p}$.

MACEDO, C.S. et al. Characterization of the isoprenoid

Rev. Bras. PI. Med., Botucatu, v.13, especial, p.574-581, 2011. 
chain of coenzyme $Q$ in Plasmodium falciparum. FEMS Microbiology Letters, Oxford, v. 207, n. 1, p. 13-20, 2002. MAIA, S.S.S. Propagação, adubação orgânica e níveis de radiação nas características anatômicas e composição de óleo essencial em Hyptis suaveolens (L.) Poit. (Lamiaceae). 2006. 105 f. Tese (Doutorado em Agronomia/ Fitotecnia) Universidade Federal de Lavras, Lavras, 2006.

MALAVOLTA, E.; GOMES, F.P.; ALCARDE, J.C. Adubos e adubações. São Paulo: NOBEL, 2002. 200 p.

MAPA (Ministério da Agricultura, Pecuária e Abastecimento). Manual de métodos analíticos oficiais para fertilizantes minerais, orgânicos, organominerais e corretivos. Brasília. 141 p. 2007.

MING, L.C. Influência da adubação orgânica na produção de biomassa e teor de óleos essenciais de Lippia Alba. Horticultura Brasileira, Brasília, DF, v. 12, n. 1, p. 49-52, 1994.

OLIVEIRA JÚNIOR, A.C. et al. Teor e rendimento de óleo essencial no peso fresco de arnica, em função de calagem e adubação. Horticultura Brasileira, Brasília, DF, v. 23, n. 3, p. 735-739, 2005.

PARK, Y.K. et al. Chemical constituents in Baccharis dracunculifolia as the main botanical origin of southeastern Brazilian propolis. Journal of Agricultural and Food Chemistry, Washington, DC, v. 52, p. 11001103, 2004.
PINTO, J.E.B.P. et al. Plantas medicinais. Lavras: UFLA, 1999, n. 58, 74 p. (Boletim Técnico). Disponível em: <http:/ /br.geocites.com/horticultura1>. Acesso em 20 jan. 2009. QUEIROGA, C.L. Estudo fitoquímico do óleo essencial de Baccharis dracunculifolia. 1989. 193 f. Dissertação (Mestrado em Química)-Universidade Estadual de Campinas, Campinas, 1989.

RAIJ, B.V. et al. Análise química para avaliação da fertilidade de solos tropicais. Campinas: Instituto Agronômico de Campinas. 285 p. 2001.

RIBEIRO, A.C.; GUIMARÃES, P.T.G.; ALVAREZ, V.V.H. Recomendação para o uso de corretivos e fertilizantes em Minas Gerais: $5^{\circ}$ aproximação. Viçosa: Comissão de Fertilidade do Solo de Minas Gerais, p. 87-91, 1999. SANTOS, M.R.A.; INNECCO,R. Adubação orgânica e altura de corte da erva-cidreira brasileira. Horticultura Brasileira, Brasília, DF, v. 22, p. 182-185, 2004.

SANGWAN, N.S. et al. Regulation of essential oil production in plants. Plant Growth Regulation, Dordrecht, v. 6, n. 34, p. 3-21, 2001.

SILVA, F.G. et al. Influence of manure and fertilizer on Baccharis trimera (Less) D.C. growth and essential oil yield. Journal of Herbs Spices \& Medicinal Plants, Birmingham, v. 12, n. 1/2, p. 1-11, 2006.

ZOMLEFER, W.B. Guide to flowering plant families. Chapel Hill: University of North Carolina Press, p. 430, 1994. 